\title{
Broad Ligament Pregnancy Through A Cesarean Scar : An Unusual One
}

\author{
Sabina Yeasmin ${ }^{1^{*}}$ \\ Tahera Begum ${ }^{2}$ \\ Md Jalal Uddin ${ }^{3}$
}

${ }^{1}$ Department of Obstetrics and Gynaecology Chattagram Maa-O-Shishu Hospital Medical College Chittagong, Bangladesh.

${ }^{2}$ Department of Community Medicine Chattagram Maa-O-Shishu Hospital Medical College Chittagong, Bangladesh.
*Correspondence to:

Dr. Sabina Yeasmin Assistant Professor

Department of Obstetrics and Gynaecology Chattagram Maa-O-Shishu Hospital Medical College Chittagong, Bangladesh.

E-mail: drsabinah@yahoo.com

Mobile: +8801914339095

\begin{abstract}
Broad ligament pregnancy is an extremely rare event with high risk of maternal mortality. Diagnosis is often late in our setting and finally made during laparotomy. It is a type of secondary abdominal pregnancy.We present a case which remained undiagnosed throughout her pregnancy till she reached to 35 weeks and unfortunately had intrauterine fetal demise when she reported to our hospital.After admission her pregnancy was induced with misoprostol but did not response. On clinical suspicion,repeat ultrasound evaluation was done by senior sinologist, which picked up the diagnosis of abdominal pregnancy. On laparotomy a broad ligament pregnancy was found with a rent in the previous Cesarean scar towards the gestational sac in the broad ligament.
\end{abstract}

Key words: Broad ligament; Ectopic pregnancy; Ultrasonography.

\section{INTRODUCTION}

Abdominal pregnancy is a rarity that only a few Gynaecologists will encounter during their professional career ${ }^{1}$. This type of pregnancy is a rare but life threatening condition, which poses considerable challenge particularly to care provider in developing countries ${ }^{2}$. It is account for $1 \%$ percent of ectopic pregnancies and maternal mortality rate as high as $20 \%{ }^{3,4}$. It may occur in any part of the abdomen but is more common in pouch of douglas and is rare in broad ligament ${ }^{5}$. Broad ligament pregnancy is one type of abdominal pregnancy also termed as interligamentous pregnancy is a rare form of ectopic pregnancy. In literature a few cases have been reported where such pregnancies reached term and even with live birth of a baby ${ }^{6-9}$. We report a case of post Cesarean 35 weeks pregnancy diagnosed to have an abdominal pregnancy by clinical and ultrasonographic evaluation, but finally found to be a broad ligament pregnancy on laparotomy.On laparotomy findings suggested that the ectopic gestation in the broad ligament has occurred through a rent in the old Cesarean scar. We share the challenges including diagnostic dilemma as well as management faced by us .

\section{CASE REPORT}

A 32-year-old female, gravida 4th, para 2+1(Abortion) having two live issues with previous 2 Cesarean section and last one 2 years back presented to our outpatient department at 35 weeks gestation and inability to perceive foetal movement for last 10 days. She had only one antenatal checkup at 33 weeks with an ultrasonography report of a primary health care centre showing viable fetus with intra-uterine growth retardation and oligohydramnios. For that, she was advised for admission, but she refused and go home. 
She was admitted in our obstetrics and gynaecology department, at 35 weeks pregnancy from her last menstrual period.She also diagnosed as gestational diabetic and $\mathrm{HbsAg}$ +ve patient. She had no complaints of pain or discomfort in abdomen. Her vital parameters were found within normal limits. On abdominal examination, uterus was 28 weeks size, soft, non-tender and clinically liquor was found to be grossly reduced. Foetal heart sound was absent. On per vaginal examination, cervix : tubular, os: closed, laterally displaced to right side and high up. Initial ultrasound report only mentioned intrauterine pregnancy with foetal death. So, pregnancy was induced with misoprostol but did not response. Since clinically we suspected some associated abnormality, patient was referred back for review ultrasonographic evaluation of abdomen by senior sonologist to know the exact nature of patholegy. On ultrasonography by a senior specialist, it appeared to be an abdominal pregnancy with foetal death. Her haemoglobin was $10.5 \mathrm{~g} / \mathrm{dL}$ and other haematological parameters including coagulation profile were within normal range.

She was taken up for surgery.Under general anaesthesia the abdomen was opened. The uterus was found to be about 10 weeks size lying on the anterior and right inferolateral aspect of the amniotic sac. The sac was found enclosed in the left broad ligament pushing the fallopian tube and the ovary upward and round ligament stretching over it (Fig 1). A diagnosis of left broad ligament pregnancy was made. Both the tube and ovary on the left side were found to be normal. Anterior wall of the sac was cut open (Fig 2). A macerated male fetus of $1 \mathrm{~kg}$ was extracted (Fig 3). Placenta was found on the medial aspect of the sac and it could be removed without causing undue haemor-rhage (Fig 4). Anterior wall of the lower segment of the uterus was found gaping and opening into the foetal sac in the left broad ligament. Uterus was lying on right anterior and cervix was on right posterior aspect of the sac. Gap on lower uterine segment was carefully repaired. A drain was placed in the cavity occupied by the fetus.Another drain was placed in the poucth of douglas Postoperatively,she recovered well without any untoward oceurrence. Stitches were removed alternately on the 8 th and 9 th postoperative day.

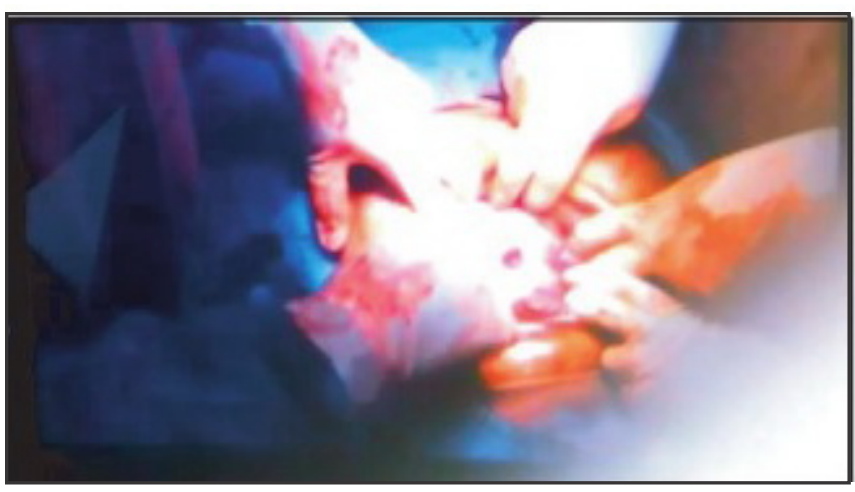

Figure 1 : Ectopic pregnancy mass 20x18cm within left broad ligament.

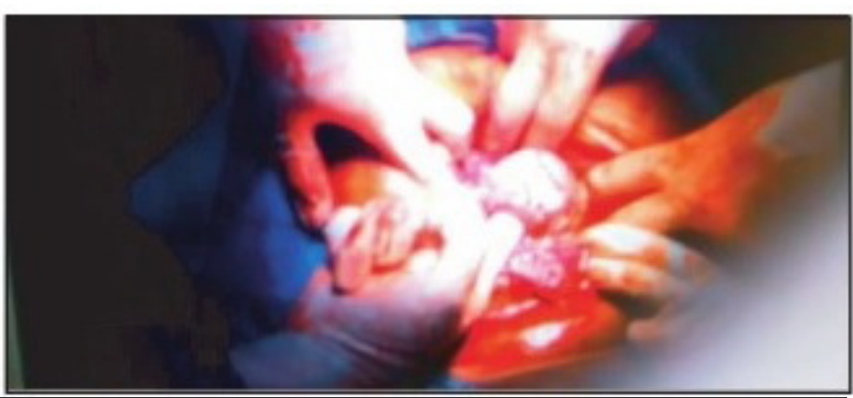

Figure 2 : Sac was open buttock of fetus showed.

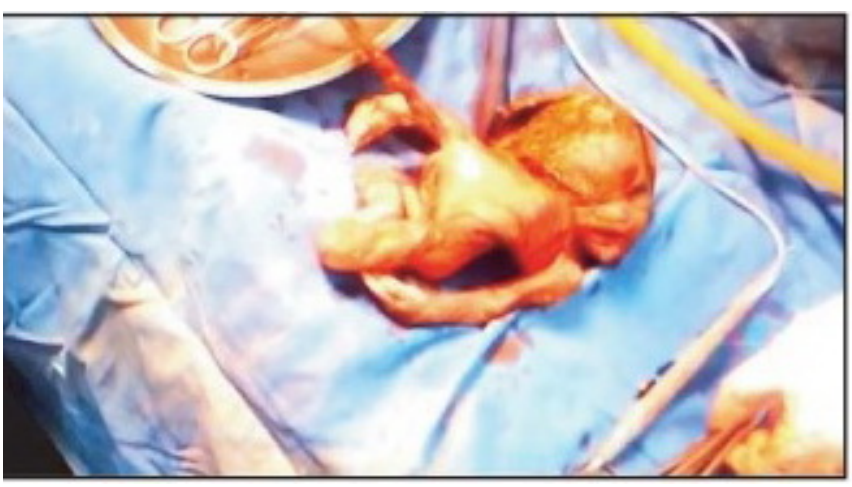

Figure 3 : Macerated fetus.

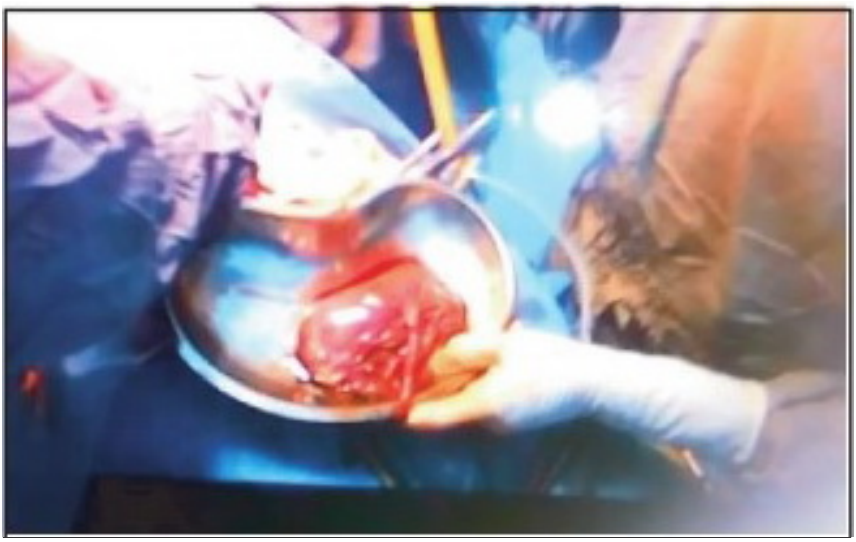

Figure 4 : Placenta.

\section{DISCUSSION}

Broad ligament pregnancy is a rare form of ectopic abelominal pregnancy. Incidence is reported as 1 in 300 ectopic pregnancies $^{6}$. It is either due to primary implantation of the zygote on the broad ligament or followed by secondary implantation to fallopian tube, ovary or other peritoneal surfaces ${ }^{5}$. Rare types of secondary abdominal pregnancies can occur after spontaneous separation of an old Cesarean section scar, after uterine perforation during a therapeutic or elective abortion, and after subtotal or total hysterectomy ${ }^{10}$. In our case, conceptus probably penetrated a weak previous Cesarean scar and got implanted between the leaves of the broad ligament. Weakness in the previous Cesarean scar may be due to previous two cesarean section and one $\mathrm{E} \& \mathrm{C}$ for incomplete abortion. 
Presentation of abdominal pregnancy can be varied from mild abdominal pain and discomfort to catastrophic internal haemorrhage, manifesting with acute abdomen and shock. Clinical suspicion is often missed when patient does not pres-ent with much symptoms. Ultrasound is the most effective method for diagnosing an abdominal pregnancy ${ }^{11}$. In our case, we confirm our diagnosis on laparotomy, even after clinical and sonographic evaluation by experienced specialists.

Early diagnosis and management is essential because a severe complications may occur due to separation of placenta at any gestational age. The rate of maternal mortality has been reported to be as high as $20 \%$ and the perinatal mortality rate ranges between $40 \%$ to $95 \%{ }^{12,13}$. So, surgical intervention is recommended as soon as an abdominal pregnancy is diagnosed. In rare instances, there may be justification for postponed surgery to allow for further foetal maturity and a better perinatal prognosis ${ }^{10}$. Kim et al. has reported a case of abdominal pregnancy diagnosed at 18 weeks of gestation and managed expectantly till foetal lung maturity with delivery of a viable baby at 34 weeks. But Martin et al. reported 15 cases of abdominal pregnancy with foetal death in all cases when diagnosed in advanced abdominal pregnancy and expectant management was done to attend better neonatal outcome ${ }^{14,15}$. Sheela et al. reported a case of broad ligament pregnancy with live birth of a baby following 10 days of conservative management to attend lung maturity ${ }^{7}$. Abdominal pregnancy having live birth has been reported by many other authors ${ }^{6,8,9}$.
Most of them were diagnosed late in pregnancy or diagnosis was made during laparotomy. Our case carried an abdominal pregnancy to 35 weeks but unfortunately got admitted to hospital after foetal demise Ultrasonography picture showing an abdominal pregnacy and the laparotomy finding of fetus in the broad ligament with a rent in lower uterine segment communicating the foetal sac, confirmed our diagnosis of broad ligament pregnancy occurring through a previous Cesarean scar. On literature search we could find a case report of broad ligament pregnancy caused through the previous Cesarean $\operatorname{scar}^{11}$.

Broad ligament pregnancy occurring through previous cesarean scar is an extremely rare condition. In our case diagnosis of abdominal pregnancy was made by ultrasonographic evaluation but final diagnosis of broad ligament pregnancy and a rent in lower segment of uterus was revealed only on laparotomy. Ultrasonography remain principal diagnostic tools to help the clinician in preoperative assessment and planning the operative management in such challenging cases.

\section{CONCLUSION}

This case of broad ligament ectopic pregnancy is reported here not only because of its rarity but also the diagnosis and management is a challenge. The value of ultrasound for the diagnosis is a mainstay but in complicated cases the repeated review of the patient is mandatory.MRI shuld be the diagnostic tool where facilities are available.

DISCLOSURE

All the authors declared no competing interest.

\section{REFERENCES}

1. Edmonds D.K. Ectopic pregnancy.Dewhurst's text book of Obstetrics \& Gynaecology. 2012;8:85

2. Rahaman J,Berkowitz R,MttyH,Gaddipati S,BrownB,Nezhat F.Minimally invasive management of advanced abdominal pregnancy.Obste Gynecol. 2004;103:1064-1068.

3. Ludwig M, Kaisi M, Bauer O, Diedrich K.The forgotten child : A case of heterotropic, intraabdominal and intrauterine pregnancy carried to term. Hum Reprod. 1999;14:1372-1374.

4. Alto WA. Abdominal pregnancy. Am Fam Physicain. 1990;41:209-214.

5. Sharma S, Pathak N, Goraya S, Mohan P. Broad ligament ectopic pregnancy. J Obstet gnecol Srilanka. 2011;33: 60-62.

6. Vierhout ME, Wallenburg HC. Intraligamentary pregnancy resulting in a live infant. Am J Obstet Gynecol. 1985;152:878-879.

7. Sheela CN, Mhaskar A, Karanth S. Advanced intraligamentary pregnancy resulting in a live birth. J Obstet Gynecol India. 2011;57:548-549.

8. Singh U, Singh N, Sankhwar P. Full-term viable broad ligament pregnancy surgically managed with favorable feto-maternal outcome. J Obstet Gynecol India. 2012;62:23-24.

9. Akhtar N. Ectopic pregnancy and full term live birth: A case report. J Postgrad Med Inst. 2011;25:181-182.

10. Damario MA, Rock JA. Ectopic pregnancy. In: Rock JA, Jones HW 3rd, editors. Te Linde's operative gynaecology. Philadelphia, PA: Lippincott Williams \& Wilkins. 2008. 798-842.

11. Rudra S,Gupta S,Taneja B K, Gupta R. Full term broad ligament pregnancy through a cesarean scar. Obstet gynecol Sci.2013;56(6):404-407.

12. Dahab AA, Aburass R, Shawkat W, Babgi R, Essa O, Mujallid RH. Full-term extrauterine abdominal pregnancy: A case report. J Med Case Rep. 2011;5:531.

13. Onan MA, Turp AB, Saltik A, Akyurek N, Taskiran C, Himmetoglu O. Primary mental pregnancy: Case report. Hum Reprod. 2005;20:807-809.

14. Kim MJ, Bae JY, Seong WJ, Lee YS. Sonographic diagnosis of a viable abdominal pregnancy with planned delivery after fetal lung maturation. J Clin Ultrasound 2012 [Epub]. http://dx.doi.org/10.1002/jcu.22010.

15. Martin JN Jr, Sessums JK, Martin RW, Pryor JA, Morrison JC. Abdominal pregnancy: Current concepts of management. Obstet Gynecol. 1988;71:549-557. 